\title{
A Study of Peptide-Peptide Interactions Using MALDI Ion Mobility o-TOF and ESI Mass Spectrometry
}

\author{
Amina S. Woods \\ NIDA, NIH, Baltimore, Maryland, USA \\ John M. Koomen, Brandon T. Ruotolo, Kent J. Gillig, \\ and David H. Russel \\ Laboratory for Biological Mass Spectrometry, Texas A and M University, College Station, Texas, USA
}

Katrin Fuhrer, Marc Gonin, Thomas F. Egan, and J. Albert Schultz

Ionwerks, Inc., Houston, Texas, USA

\begin{abstract}
Matrix-assisted laser desorption ionization ion mobility coupled to orthogonal time-of-flight mass spectrometry (MALDI-IM-oTOF MS) is evaluated as a tool for studying non-covalent complex (NCX) formation between peptides. The NCX formed between dynorphin 1-7 and Mini Gastrin I is used as a model system for comparison to previous MALDI experiments (Woods, A. S.; Huestis, M. A. J. Am. Soc. Mass Spectrom. 2001, 12, 88-96). The dynorphin 1-7/Mini Gastrin I complex is stable after more than a ms drift time through the He filled mobility cell. Furthermore, the effects of solution pH on NCX ion signal intensity is measured both by MALDI-IM-MS analysis and by nanoelectrospray mass spectrometry. When compared to the previous MALDI study this work shows that all three techniques give similar results. In addition, fragmentation can be observed from of the non-covalent complex parent ion that occurs prior to TOF mass analysis but after mobility separation, thus providing NCX composition information. (J Am Soc Mass Spectrom 2002, 13, 166-169) () 2002 American Society for Mass Spectrometry
\end{abstract}

$\mathrm{N}$ on-covalent interactions have been studied previously, most often using electrospray ionization (ESI) mass spectrometry [1]. One of the motivations of this approach is the possibility that the structure and conformations of the gas-phase ions could retain clues to biological activity. However, non-covalent complexes are often in the presence of interferants (i.e., salts, detergents, or other solubilizing agents), which suppress ESI, making MALDI a more suitable ionization method. Many types of non-covalent complexes have also been successfully analyzed with MALDI as shown in Farmer and Caprioli's excellent review [2]. Furthermore, developing the ability to directly identify non-covalent complexes on a bio-surface such as a tissue slice or a protein array depends on first demonstrating the capability of MALDI analysis of complexes by testing it on model systems.

A recent study of peptide-peptide interactions [3]

Published online December 3, 2001

Address reprint requests to Dr. A. S. Woods, Chemistry and Drug Metabolism, Intramural Research Program, NIDA, NIH, 5500 Nathan Shock Drive, Baltimore, MD 21224, USA. E-mail: awoods@intra.nida.nih.gov has demonstrated that MALDI can be used to observe the formation of non-covalent complexes involving a salt bridge between an acidic peptide containing two or more adjacent Glu or Asp and a basic peptide containing two or more adjacent Arg or the Arg-Lys-Arg motif. The guanido group of the Arg side chain has a net positive charge that can be neutralized by removing a proton while the carboxyl groups of Asp and Glu have resonance structures where one pair of electrons from each oxygen is delocalized over the $\pi$ molecular orbital system. Therefore, the proton from the Arg side chain is attracted to the delocalized lone pair of electrons on the Asp or Glu side chain carboxyl group [4]. These interactions between very close oppositely charged groups in peptides and proteins are known as salt bridges [5]. The detection of such complexes by MALDI is strongly dependent on the peptide-matrix solution $\mathrm{pH}[3,6-8]$. Anfinsen [9] has shown that loss of biological function can come about through disruption of the tertiary structure resulting from $\mathrm{pH}$, temperature, or pressure, leading to the disruption of non-covalent bonds.

In this work the dynorphin-minigastrin complex model system is examined with MALDI-IM-oTOF MS 
[10]. Ion mobility has been used extensively to separate ions of small organic molecules in the gas phase on the basis of collision cross section-to-charge ratios $(\Omega / z)$ [11-16]. IM/MS has been used to determine the conformations of mass identified peptide and protein ions as well to investigate the gas-phase dynamics of biological molecules [17-20]. Recently, ESI [14, 15] and MALDI [10] have been used in combination with IM drift cells. At first glance, the combination of ESI and mobility would appear to be the most suitable method for the analysis of non-covalent complexes because of the low amount of initial internal energy imparted to the ions. Nevertheless, MALDI can also impart a low amount of internal energy to desorbed molecules.

MALDI desorption into the high-pressure (5-10 torr $\mathrm{He}$ ) ion mobility drift cell provides a different set of ionization conditions from ESI or high-vacuum MALDI. For example, a comparison was recently made between spectra from two identical peptide digest samples using high vacuum MALDI and MALDI-IM-TOF MS [21]. A greater percent of amino acid coverage for the peptides investigated was observed for MALDI-IM-TOF MS than for conventional high-vacuum MALDI-TOF. This may imply that the presence of buffer gas increases stabilization of ions or promotes additional ionization pathways that are absent when ions are ejected from the surface into vacuum. By analogy, interaction with the He gas may stabilize weakly bonded non-covalent complex ions that might not otherwise be observed in conventional high vacuum spectrometers.

The dual objectives of this study are: To determine if NCX ions can survive transit through the IM drift cell, and to determine if non-covalent complexes acquire a gas-phase conformation radically different from that of corresponding constituent peptides. The analytical utility of post-mobility cell fragmentation, which allows for the unambiguous association between fragment and precursor ions, is also discussed.

\section{Materials and Methods}

A cGMP dependent protein kinase inhibitor peptide [RKRARKE (943.1)], dynorphin 1-7 [YGGFLRR (MW = 868.20] and Mini Gastrin I [LEEEEEAYGWMDF- $\mathrm{NH}_{2}$ $(\mathrm{MW}=1646.7)]$ were purchased from Sigma (St. Louis, $\mathrm{MO}$ ). The matrix, 6-aza-2-thiothymine (ATT) was purchased from Aldrich (Milwaukee, WI). The matrix was prepared as a saturated solution in 1:1 deionized water: ethanol. All peptides were dissolved in deionized water to a concentration of $100 \mathrm{pmol} / \mu \mathrm{L}$. MALDI samples were prepared by mixing the acidic and basic peptides 1:1:1 with ATT in deionized water or a mixture of 1:1 ethanol:water. The matrix mixture was adjusted to $\mathrm{pH} 7$ with ammonium bicarbonate and to $\mathrm{pH} 3$ with formic acid. 3-5 $\mu$ l were deposited on the probe tip for MALDI-IM analysis.

Electrospray mass spectra were acquired on an MDS Sciex (Concord, Ontario, CA) QStar Pulsar hybrid quadrupole time-of-flight mass spectrometer in nega- tive ion mode. Peptide solutions of 25 to $50 \mathrm{pmol} / \mu \mathrm{l}$ in 1:1 $\mathrm{H}_{2} \mathrm{O}: \mathrm{EtOH}$ at $\mathrm{pH} 7$ were electrosprayed using the Protana (Odense, Denmark) nanoelectrospray source. The ion spray voltage was $1200 \mathrm{~V}$ and no backpressure was used to aid nebulization. The nozzle skimmer potential was minimized $(5 \mathrm{~V})$ to avoid fragmentation in that region.

The MALDI IM-TOF instrument was built in-house, and has been described in detail previously [10, 22]. IM/MS data handling is similar to that of GC-TOF or LC-TOF instruments. The MALDI sample is introduced through a standard vacuum interlock into an ion mobility drift cell constructed from a series of concentric stainless steel rings (totaling $29.5 \mathrm{~cm}$ in length). A nitrogen laser (VSL-337ND, Laser Science Inc., Franklin, MA.), operated at $20 \mathrm{~Hz}$, is used for MALDI ionization. The cell is operated at 5-10 torr He with a total drift voltage of 1500 volts (around $10 \mathrm{~V} \mathrm{~cm}^{-1}$ torr $^{-1}$ ) and is used to separate MALDI ions on the basis of their $\Omega / z$ in the first dimension. As separated ions exit the mobility drift cell their $m / z$ is determined by pulsing an extraction plate, sending the sampled packet of ions to a time-of-flight analyzer. Total flight times in the mass spectrometer are under $20 \mu \mathrm{s}$. A mass spectrum is stored for a series of drift times so that a plot of ion $\mathrm{m} / \mathrm{z}$ as a function of mobility drift time can be reconstructed from the data. Under the standard operating conditions of the ion mobility drift tube, drift times range from hundreds of $\mu$ s to several ms, and mobility resolution (defined as the drift time divided by peak width at half-height) of 60 is routinely achieved. The small linear time-of-flight mass spectrometer is $20 \mathrm{~cm}$ in length, capable of 400 mass resolution, and can acquire spectra at an extraction frequency $50 \mathrm{KHz}$. All mass mobility contour plots were produced using Transform, and surface plots were constructed using the IDL programming language, both of which are available from Research Systems (Boulder, CO).

\section{Results and Discussion}

As noted in Figure 1, a near-linear relationship exists between $\mathrm{m} / \mathrm{z}$ and mobility drift time for a homologous series of singly charged ions, allowing classes of ions that posses different mass/mobility trends to be distinguishable. For example, Figure 1 contains signals that correspond to peptide ions and $\mathrm{C}_{60}{ }^{+\cdot} / \mathrm{C}_{70}{ }^{+\cdot}$. The fullerenes posses a very different homology and gasphase conformation than peptide ions, and are, therefore, easily discernable from the peptide related signals. Moreover, within a homologous series, there are smaller differences in mobility between conformers of ions that can be useful for elucidation of gas-phase ion structure when combined with computational modeling and collision cross-section calculations.

The $\mathrm{pH}$ dependence of the dynorphin/Mini Gastrin non-covalent complex ion signal is illustrated in Figure 1a ( $\mathrm{pH} 3)$, Figure $1 \mathrm{~b}(\mathrm{pH} 5)$, and Figure 1c $(\mathrm{pH} 7)$. The intensity of the complex signal is decreased at $\mathrm{pH} 3$ 


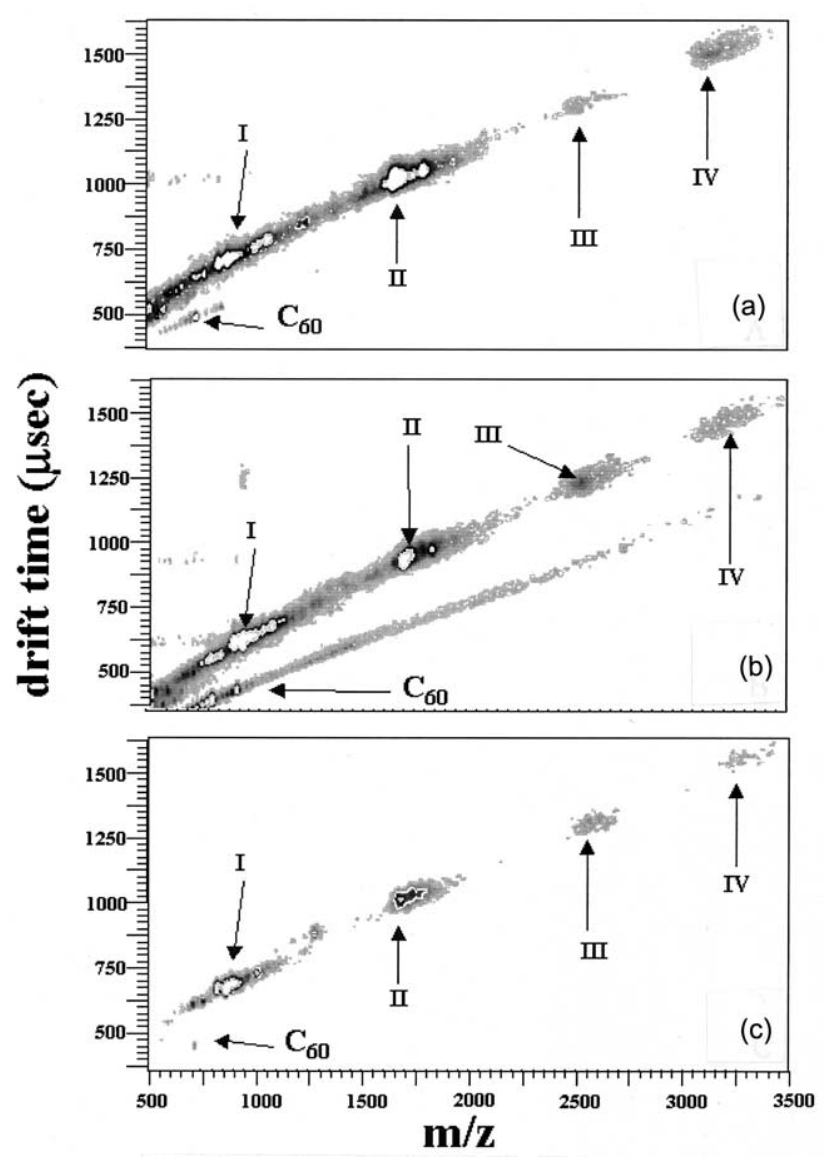

Figure 1. Contour plots of mobility drift time versus mass-tocharge ratio for ion signals corresponding to dynorphin 1-7 (I), Mini Gastrin I (II), the non-covalent complex between dynorphin 1-7 and Mini Gastrin I (III), and the homodimer of Mini Gastrin I (IV) from ATT matrix at $\mathrm{pH} 3(\mathbf{a}), \mathrm{pH} 5$ (b), and $\mathrm{pH} 7$ (c). $\mathrm{C}_{60}$ was added as an internal calibrant.

when compared to that observed at $\mathrm{pH} 5$ or 7 . Mini Gastrin I dimer ions are seen at all $\mathrm{pH}$ values. Similar results for the NCX were observed for a mixture of RKRARKE and Mini Gastrin I (data not shown). The ion signals indicate that the non-covalent complexes were stable enough to survive a $1.4 \mathrm{~ms}$ transit through the mobility cell and the o-TOF. All non-covalent complexes as well as the uncomplexed peptide ions lie along the same mobility/mass-to-charge ratio $(\mathrm{m} / \mathrm{z})$ trend line. Thus, the ionized gas-phase noncovalent complex shows no gross conformational changes relative to the individual constituent peptides.

Mixtures of Mini Gastrin I and basic peptides (e.g., dynorphin 1-7 or RKRARKE) were also examined by electrospray MS in negative ion mode. In each case, ion signals corresponding to the non-covalent complex between the acidic and the basic peptide were observed but no homodimers were detected in these ESI spectra. For example, the triply charged ion for the dynorphin 1-7-Mini Gastrin I complex is observed at $\mathrm{pH} 7$ (Figure $2 \mathrm{a})$.When the same mixture is acidified $(\mathrm{pH}<2)$, ion signal for the complex was not observed, only the individual peptides were detected (Figure 2b). The data

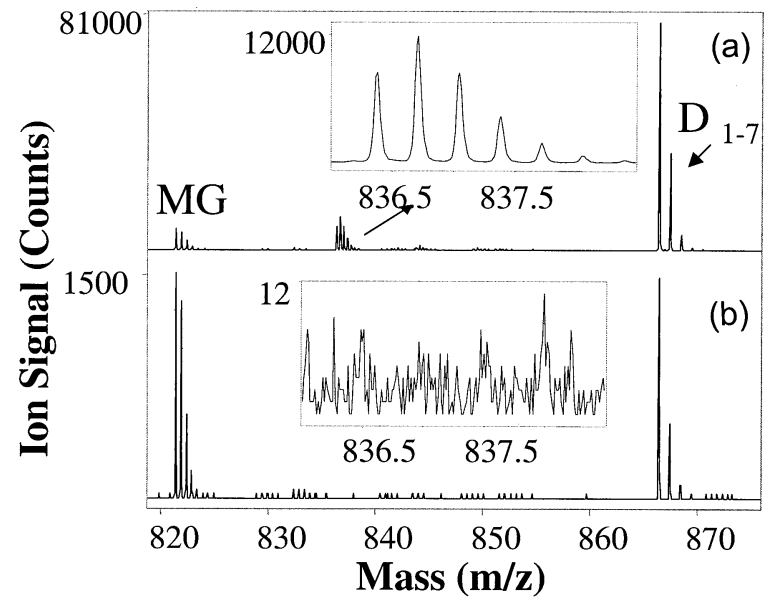

Figure 2. Negative ion electrospray mass spectra of dynorphin 1-7 $\left(\mathrm{D}_{1-7}\right)$ Mini Gastrin I (MG) and $\mathrm{D}_{1-7}-\mathrm{MG}$ complex at $\mathrm{pH} 7$ (a) and $\mathrm{D}_{1-7}$ and $\mathrm{MG}$ only at $\mathrm{pH} 2(\mathbf{b})$.

suggests that the $\mathrm{pH}$ of the electrospray solution, and that of the matrix/analyte solution, determines whether or not a non-covalent complex forms between two peptides. Furthermore, the results from ESI and MALDI-IM corroborate the results previously obtained by MALDI [1].

In addition to observing changes in ion signal with $\mathrm{pH}$, ion mobility coupled to TOF MS allows for the direct observation of peptide complex dissociation that occurs after the drift tube and before orthogonal extraction for TOF MS analysis. Fragmentation of the NCX after exiting the mobility cell is illustrated in Figure 3, a zoomed view of Figure 1b. The non-covalent complex between Mini Gastrin I and dynorphin 1-7 undergoes fragmentation after mobility separation has taken place, resulting in a signal corresponding to dynorphin 1-7 at the same mobility drift time as the much larger noncovalent complex. This fragmentation pathway was expected, as it represents a low energy channel of

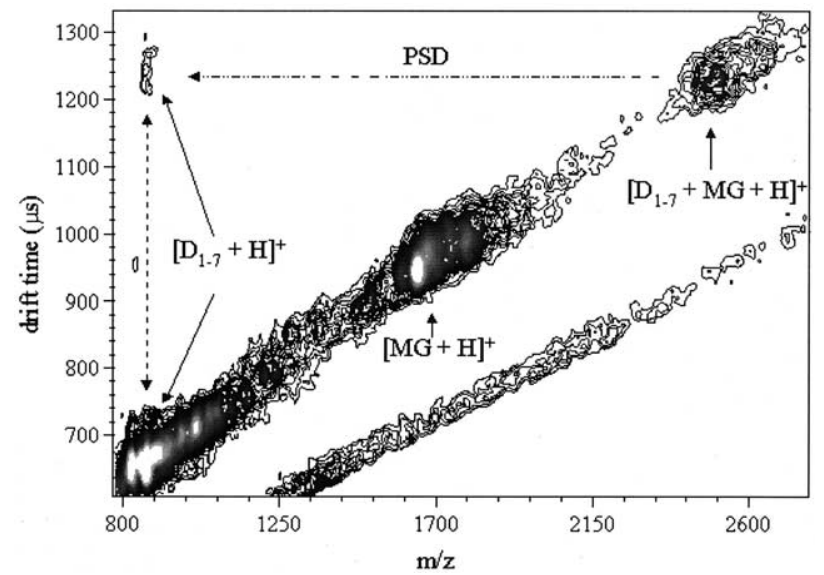

Figure 3. Mobility mass contour plot of ion signals observed from a mixture of dynorphin 1-7 and Mini Gastrin I with ATT matrix. Post-mobility cell fragmentation is indicated by the dashed line, and the fragment ion signal observed is correlated to the dynorphin 1-7 signal observed at an earlier arrival time. 
dissociation for such a complex. In addition, the observation of charge retention by dynorphin 1-7 is consistent with the highly basic primary structure of the peptide.

\section{Conclusions}

At $\mathrm{pH}$ values of the peptide solutions of less than 3, no ion signals for the complexes are observed by any mass spectrometric method used. However, as the $\mathrm{pH}$ was raised to 5 or 7, MALDI-IM-oTOF MS and ESI-MS could detect ion signals corresponding to the non-covalent complex, verifying results obtained by MALDI-TOF MS. No signals corresponding to homodimer formation were present in ESI spectra. However, the NCX signals observed under any of the three ionization conditions exhibited similar behavior as a function of solution $\mathrm{pH}$. Therefore, the three methods (MALDI-MS, MALDI-IMMS, and ESI-MS) give similar information about peptide-peptide complex formation.

All of the contour plots of mobility drift time versus $\mathrm{m} / \mathrm{z}$ show that the individual peptides, their complex, and homodimers exhibit the same relationship between drift time and $\mathrm{m} / \mathrm{z}$. Thus, no large change in conformation was observed for the non-covalent complex relative to its constituent peptides. Post-mobility cell fragmentation can be observed for these complexes illustrating the additional utility of coupling mobility drift cells to TOF MS. The direct correlation of fragment ions with their mobility selected precursor parent ions is especially useful for composition analysis of species, such as non-covalent complexes.

Future work will focus on imaging bio-surfaces within which biologically relevant non-covalent complexes exist. Work presented here will form the foundation for the continued development of MALDI-IMoTOF MS as a sensitive method for imaging such surfaces.

\section{Acknowledgments}

Texas A\&M is grateful for support from the NSF (CHE-929966) and DOE, Division of Chemical Sciences, Basic Energy Science
(DE-FG03-95ER14505). Ionwerks was partially supported by the NIH through SBIR phase II grant 2 R44 GM57736-02. The authors thank Dr. Marilyn Huestis from NIDA for her intellectual input.

\section{References}

1. Loo, J. A. Mass Spectrom. Rev. 1997, 16, 1-17.

2. Farmer, T. B.; Caprioli, R. M. J. Mass Spectrom. 1998, 33, 697-704.

3. Woods, A. S.; Huestis, M. A. J. Am. Soc. Mass Spectrom. 2001, $12,88-96$.

4. Kyte, J. Structure in Protein Chemistry. Garland Publishing, Inc.: New York, 1995 Chap II.

5. Creighton, T. E. Proteins Structure and Molecular Properties; 2nd ed. W. H. Freeman and Company: New York, 1993, Chap I.

6. Woods, A. S.; Buchsbaum, J. C.; Worrall, T. A.; Cotter, R. J. Berg. J. M. Anal. Chem. 1995, 67, 4462-4465.

7. Lin, S.; Cotter, R. J.; Woods, A. S. Proteins: Structure, Function and Genetics 1998, 2, 12-21.

8. Lin, S.; Long, S.; Ramirez, S. M.; Cotter, R. J.; Woods, A. S. Anal. Chem. 2000, 72, 2635-2640.

9. Anfinsen, C. B. Science 1973, 181, 223-230.

10. Gillig, K. J.; Ruotolo, B. T.; Stone, E. G.; Russell, D. H.; Fuhrer K.; Gonin, M.; Schultz, J. A. Anal. Chem. 2000, 72, 3965-3971.

11. McDaniel, E. W.; Mason, E. A. The Mobility and Diffusion of Ions in Gases. Wiley: New York, 1973; 31-93.

12. Mason, E. A. Plasma Chromatography. Carr, T. W., Ed.; Plenum Press: New York, 1984; 80-83.

13. Wyttenbach, T.; vonHelden, G.; Bowers, M. T. J. Am. Chem. Soc. 1996, 118, 8355-8364.

14. Counterman, A. E.; Clemmer, D. E. J. Am. Chem. Soc. 1999, 121, 4031-4039.

15. Wu, C.; Siems, W. F.; Asbury, G. R.; Hill, H. H., Jr. Anal. Chem. 1998, 70, 4929-4938

16. Wu, C.; Siems, W. F.; Klasmeier, J.; Hill, H. H. Anal. Chem. 2000, 72, 391-395.

17. Kinnear, B. S.; Hartings, M. R.; Jarrold, M. F. J. Am. Chem. Soc. 2001, 123, 5660-5667.

18. Gidden, J.; Bushnell, J. E.; Bowers, M. T. J. Am. Chem. Soc. 2001, $123,5610-5611$.

19. Srebalus, C. A.; Li, J.; Marshall, W. S.; Clemmer, D. E. Anal. Chem. 1999, 71, 3198-3927.

20. Jarrold, M. F. Annu. Rev. Phys. Chem. 2000, 51, 179-207.

21. Ruotolo, B. T.; Gillig, K. J.; Stone, E. G.; Russell, D. H.; Fuhrer, K.; Schultz, J. A. Int. J. Mass Spectrom. to be published.

22. Gillig, K. J.; Russell, D. H. International application published under the Patent Cooperation Treaty WO 01/65589 A1. 